\title{
A holistic approach to healthy ageing: How can people live longer, healthier lives?
}

PC Calder ${ }^{1}$, SR Carding ${ }^{2}$, G Christopher ${ }^{3}$, D Kuh ${ }^{4}$, SC Langley-Evans ${ }^{5 *}$, and H McNulty ${ }^{6}$

${ }^{1}$ Faculty of Medicine, University of Southampton, Southampton, United Kingdom and NIHR Southampton Biomedical Research Centre, University Hospital Southampton NHS Foundation Trust and University of Southampton, Southampton, United Kingdom

${ }^{2}$ Quadram Institute Bioscience and Norwich Medical School, University of East Anglia, Norwich, United Kingdom

${ }^{3}$ Faculty of Health and Applied Sciences, University of the West of England, Bristol, United Kingdom

${ }^{4}$ Medical Research Council Unit for Lifelong Health and Ageing, University College London, London, United Kingdom

${ }^{5}$ School of Biosciences, University of Nottingham, Sutton Bonnington, United Kingdom

${ }^{6}$ Nutrition Innovation Centre for Food and Health, School of Biomedical Sciences, Ulster University, Coleraine, United Kingdom

*Corresponding author

Professor Simon Langley-Evans, School of Biosciences, University of Nottingham, Sutton Bonington, Loughborough, LE12 5RD, United Kingdom.

\section{Simon.Langley-Evans@nottingham.ac.uk}

Keywords: Ageing; Nutrition; Genetics; Microbiome; Cognition 


\section{Abstract}

Background: Although lifespan is increasing there is no evidence to suggest that older people are experiencing better health in their later years than previous generations. Nutrition, at all stages of life, plays an important role in determining health and wellbeing.

Method: A roundtable meeting of United Kingdom (UK) experts on nutrition and ageing considered key aspects of the diet-ageing relationship and developed a consensus position on the main priorities for research and public health actions that are required to help people live healthier lives as they age.

Results: The group consensus highlighted the requirement for a life course approach, recognising the multifactorial nature of the impact of ageing. Environmental and lifestyle influences at any life stage are modified by genetic factors and early development. The response to the environment at each stage of life can determine the impact of lifestyle later on. There are no key factors that act in isolation to determine patterns of ageing and that combinations of environmental and social factors drive healthy or unhealthy ageing. Too little is known about how contemporary dietary patterns and sedentary lifestyles will impact upon healthy ageing in future generations and this is a priority for future research.

Conclusions: There is good evidence to support change to lifestyle (i.e. diet, nutrition and physical) activity in relation to maintaining or improving body composition, cognitive health and emotional intelligence, immune function and vascular health. Lifestyle change at any stage of life may extend healthy lifespan, but the impact of early changes appears to be greatest.

\section{Introduction}

The global population is living longer. Between 2015 and 2050, the proportion of the world's population aged over 60 years will nearly double from $12 \%$ to $22 \%^{(1)}$, and by 2020 the number of 
people aged 60 years or over will outnumber that of children below the age of 5 years ${ }^{(1)}$. Although lifespan is increasing, there is no strong evidence to suggest that older people are experiencing better health in their later years than previous generations ${ }^{(2,3)}$ and incidence rates for major diseases such as osteoporosis or type-2 diabetes are increasing ${ }^{(4,5)}$. Increases in lifespan appear to be outstripping increases in healthspan, so, with life expectancy increasing, what can be done to help people live longer, healthier lives? For the individual this could enable an extended working life or the pursuit of interests later in life. The broader benefits to society could include an increased workforce and a reduction of costs to health and social care services.

A roundtable meeting, supported by Merck Consumer Healthcare UK, was held in London in October 2017 to consider a holistic approach to ageing and the key factors that could be optimised to help individuals to live a longer, healthier life. The six panel members (authors of this review) and chair were selected from a range of scientific disciplines and experience including nutritional immunology (Calder), immunology and microbiology (Carding), cognitive ageing (Christopher), life course epidemiology (Kuh), early life nutrition (Langley-Evans) and human nutrition and dietetics (McNulty). The objectives of the meeting were to identify the key aspects of age-related functional decline and to develop recommendations as to how these factors could be positively influenced.

\section{Healthy ageing in the $21^{\text {st }}$ Century}

The World Health Organization (WHO) outlines a model of healthy ageing in its 'World Report on Ageing and Health' that identifies two primary factors - intrinsic capacity and functional ability ${ }^{(6)}$. The report highlights that rather than the presence or absence of disease, these primary factors are the most important considerations for healthy ageing ${ }^{(6,7)}$.

Intrinsic capacity is defined as the composite of all the physical and mental (including psychosocial) capacities that an individual can draw on at any one point in time ${ }^{(6)}$. It is important to note that individual differences here are considerable, with no operational definition of overall intrinsic 
capacity or how it changes with age, although there is growing evidence from longitudinal studies about the shape of the trajectories of its individual components ${ }^{(8,9)}$. There is also no universallyagreed age at which people are defined as 'being old'. Some people aged in their 80 s retain the intrinsic capacity of their youth, yet others will decline at a much younger age.

Intrinsic capacity is only one dimension of the functioning of an older person ${ }^{(7)}$. Interaction with the immediate environment (and indeed the characteristics of that environment) will also determine what a person can do. For example, a person whose movement is restricted in older age will show improved function if they have access to mobility aids, live in a supportive environment and can access facilities such as shops. This combination of the intrinsic capacity of the person, the environmental characteristics and how the two interact is defined as an individual's 'functional ability'. The WHO report ${ }^{(6)}$ defines healthy ageing as 'the process of developing and maintaining the functional ability that enables wellbeing in older age'. This reflects the ongoing interaction between an individual and the environment in which they live. For the purposes of this review, whilst accepting the role that the environment will play in healthy ageing, the focus will be on a person's intrinsic capacity and the ability to influence it.

\section{Key factors that influence ageing/intrinsic capacity}

According to the WHO, three disorders dominate mortality in people aged over 60 years - ischaemic heart disease, stroke and chronic obstructive pulmonary disease ${ }^{(6)}$. The greatest causes of extended periods living with disability are sensory impairments, back and neck pain, chronic obstructive respiratory disease, depressive disorders, osteoporosis, falls, diabetes, dementia and osteoarthritis $^{(6)}$. These conditions may co-exist, and increasingly do so as a function of age. Studies have highlighted a range of factors linked to these conditions, many of which are influenced by the socio-economic environment into which a person is born and raised. 
There is considerable evidence showing a link between poorer health outcomes, early morbidity and early mortality with lower socio-economic status ${ }^{(10,11)}$. Furthermore, the area in which a person lives can influence health above and beyond that observed for individual socioeconomic factors. One recent study showed that older adults living in areas with the greatest socioeconomic deprivation, compared with those living in areas of least deprivation, had poorer health profiles, higher disease risk factors and worse cognitive function ${ }^{(12)}$.

As shown in Fig. 1, each tissue, organ or system can be viewed as having an intrinsic capacity that enables it to carry out its structural and functional roles. This capacity generally relates to the numbers of functional units or cells that are present; for example the number of nephrons in the kidney, the number of islets in the pancreas or the amount of mineral deposited in the skeleton ${ }^{(13)}$. Ageing leads to loss of these functional units, and when a certain low level is reached, declining physiological function can lead to morbidity ${ }^{(14)}$. The need for a life course approach to ageing is increasingly recognised as evidence accrues that environmental factors across life impact on intrinsic capacity in later life ${ }^{(8,15,16)}$. Many of the broader environmental factors, including the living environment, may be outside of the control of an individual. Environmental factors during growth and development will determine the peak instrinsic capacity of organs and systems, and may also affect its rate of decline. The adult environment determines how long the peak or plateau is maintained and also the rate at which intrinsic capacity declines ${ }^{(8)}$. For example, peak bone mass (the degree of mineral laid down in the skeleton) is attained in the third decade of life and thereafter bone mass declines with an accelerated loss of mineral particularly at the menopause in women $^{(17,18)}$. The level of peak bone mass is shaped by a range of factors in fetal life, as well as by calcium intake in childhood and adolescence ${ }^{(19,20,21)}$. Later bone loss is related to vitamin D deficiency, smoking and a lack of physical activity. Other dimensions of intrinsic capacity, such as muscle and lung function show similar lifetime trajectories and share some of these risk factors $^{(22,23,24)}$. 


\section{Cognitive function and dementia}

Dementia, one of the most common disorders linked to ageing ${ }^{(25)}$, affects an estimated 46.8 million people worldwide and is projected to affect over 131 million people by $2050^{(26)}$. Cognitive function declines with age, ranging from relatively minor everyday slips of action, through subjective cognitive decline, mild cognitive impairment $(\mathrm{MCl})$, then to major or mild neurocognitive disorder/dementia in some instances. Up to $50 \%$ of those with $\mathrm{MCl}$ are predicted to develop dementia within 5 years ${ }^{(27)}$. A recent comprehensive report identified a model of modifiable risk factors for dementia that occur across the lifespan, highlighting the potential for effective prevention through early interventions that target these risk factors and thereby transforming the future for society ${ }^{(28)}$. Increasing age and genetic susceptibility are the biggest risk factors for developing dementia. Other medical conditions and lifestyle factors linked to an increased risk of dementia include smoking, diabetes, physical inactivity and infrequent involvement in mentally or socially stimulating activities ${ }^{(29)}$.

\section{The role of nutrition in cognitive function}

Emerging scientific evidence in this area implicates deficiencies of certain nutrients in cognitive decline whilst demonstrating that better nutritional status may be important in preserving cognition in older adults ${ }^{(30)}$. Higher intakes of fish or fruits and vegetables have been linked with better cognitive health ${ }^{(31,32)}$. Likewise certain dietary patterns, particularly the Mediterranean diet (characterised by higher intakes of olive oil, fruit, vegetables, wholegrains, fish), are of interest in terms of the potential protective effects against cognitive decline in ageing. Adherence with the Mediterranean diet was associated with lowering cardiovascular risk factors, improved immune health ${ }^{(33,34)}$, and larger cortical thickness (in turn an indication of lower risk of cognitive impairment) 
in studies using magnetic resonance imaging $(\mathrm{MRI})^{(35)}$, whilst supplementation of the Mediterranean diet with olive oil or nuts was associated with improved cognitive function ${ }^{(36)}$.

Apart from investigations of food types and dietary patterns, much research focuses on the roles of specific nutrients in relation to cognition in older age. Key nutrients considered to protect cognitive function are omega-3 polyunsaturated fatty acids (PUFAs), polyphenols, vitamin D and B-vitamins. In relation to the role of omega-3 PUFAs, the evidence suggests protective effects in cognitively impaired individuals, but not in the treatment of people with existing dementia ${ }^{(37,38)}$. The most convincing evidence in relation to polyphenols comes from a 3-month intervention study showing significant increases in cerebral blood volume in the dentate gyrus as measured by functional MRI $(\mathrm{fMRI})$ in response to a high flavanol treatment ${ }^{(39)}$. Lower serum vitamin $\mathrm{D}$ concentrations were associated with worse cognitive outcomes ${ }^{(40)}$ and accelerated cognitive decline in longitudinal studies $^{(41)}$, whilst higher vitamin D status was associated with greater brain volumes in MRI studies $^{(42)}$.

The totality of scientific evidence at this time most strongly supports roles for folate and the metabolically related B-vitamins (B12 and B6) in protecting cognitive function in older age ${ }^{(30)}$. These B-vitamins are required for one-carbon metabolism where they act as co-factors in DNA synthesis and repair, amino acid metabolism and in the methylation of phospholipids, proteins, neurotransmitters and DNA. Low status of folate or related B-vitamins may thus contribute to cognitive dysfunction by impairing methylation processes, in turn perturbing gene expression in the beta amyloid pathway or reducing the activity of protein phosphatase- $2 \mathrm{~A}^{(43)}$. It is notworthy that although vitamin B12 (cobalamin) is synthesized by some human gut microbes, there is competition between the gut microbiota and the host for dietary cobolamin as the great majority of gut microbes require exogenous corrinoids for their metabolism and survival ${ }^{(44)}$. Thus individuals with high numbers of bacteria in their intestine have low cobolamin status ${ }^{(44)}$. Lower status of folate, vitamin 
B12 and /or vitamin B6 (or higher concentrations of the related metabolite homocysteine) are associated with cognitive dysfunction in observational studies ${ }^{(43)}$, while randomised trials with these $B$ vitamins have shown improved cognitive performance after 2 years ${ }^{(45,46)}$ and a reduced rate of brain atrophy determined using $\mathrm{MRI}^{(47,48)}$ in older adults. Not all studies support roles for B vitamins, however, including one notable meta-analysis which found no beneficial effect of either folic acid or vitamin B12 on cognition in older age ${ }^{(49)}$. The latter findings are not widely accepted by experts in this area, however, primarily owing to the inclusion criteria used to select participants for the trials $^{(50)}$.

Future studies should address the gaps in the evidence-base supporting the role of nutrition in cognitive health, in particular in identifying optimal nutrient intake levels required to protect cognitive function in ageing. Further well-designed randomised controlled trials (RCTs) are needed, especially those targeting older people with low nutrient status, and ideally measuring outcomes using brain imaging, along with the more typical questionnaire-based assessments of cognitive performance used in human studies.

\section{The role of nutrition in other aspects of ageing}

A decline in organs and systems is a normal feature of ageing. In some cases the decline may be quite rapid, with for example the menopause bringing about a cessation of reproductive function in women with the associated hormonal changes affecting other systems. For example, loss of oestrogen results in both loss of bone mineral and increased cardiovascular risk ${ }^{(8,51)}$. Other agerelated changes are more gradual in nature and can be exacerbated or offset by nutrition-related factors. For example, renal function declines with age and this decline is greatly accelerated by impaired glucose homeostasis ${ }^{(52)}$. The delivery of nutrients is, however, itself compromised by ageing as a result of loss of dentition, gum disease or impairment of the sense of taste and smell. 
Alterations in the balance of the production of or response to appetite and satiety hormones, difficulty in swallowing, slower gastric emptying, atrophy of cells in the stomach, bacterial overgrowth of the small intestine and diverticulitis can all impact on intake and absorption of nutrients ${ }^{(53)}$. In addition individuals may prefer or rely on processed foods which are energy dense but nutrient poor which can be cheaper and quicket to prepare than fresh food.

The B vitamins, particularly folate, may also play a role in vascular health and a number of large supplementation trials have found that folate-based interventions can significantly reduce the risk of stroke, but not coronary heart disease ${ }^{(54,55)}$. Nutrition has been shown to have a direct impact on the age-related decline of the immune system (immunosenescence) ${ }^{(53,56)}$. This decline increases susceptibility to infections and impairs responses to vaccination ${ }^{(57,58)}$. Thymic involution plays a key role in immunosenescence. A greater immune decline has been linked to low dietary levels of protein, $B$ vitamins, vitamin $E$, iron and zinc ${ }^{(59,60,61,62)}$. Zinc has been shown to improve the immune response in older people ${ }^{(63)}$.

As discussed above, loss of bone mineral is a feature of ageing and increases risk of osteoporosis, which by the age of 80 years is observed in more than $50 \%$ of women and $10 \%$ of men. Maintaining physical activity combined with a healthy weight, and ensuring recommended intakes of calcium and vitamin $\mathrm{D}$ can slow the rate of bone loss, with some evidence suggesting that supplementation can have short-term benefits ${ }^{(64,65)}$. In individuals of particular genotypes caffeine avoidance may also be beneficial $^{(66)}$. Resident microbes of the lower gastrointestinal (GI)-tract (the intestinal microbiota) may also play a role in maintaining bone health. In individuals where intestinal bacteria promote metabolism of phytoestrogens (e.g. soy isoflavones) to equol, bone loss is inhibited by intake of phytoestrogen-rich sources ${ }^{(67)}$. Sarcopenia is another feature of ageing as the rate of muscle protein breakdown can exceed protein synthesis ${ }^{(68)}$, particularly where infection- and trauma-related malnutrition are present ${ }^{(68)}$. 
There are no simple nutritional solutions for age-related structural and functional decline and some of the steps which may be beneficial for some organ systems may have no, or unwanted, impact elsewhere. For example, while calcium supplementation may limit bone loss, for some women with good intake from the diet, excessive calcium may promote cardiovascular disease ${ }^{(69)}$. Interactions of diet with other factors become important too rendering some one-size-fits-all approaches to health promotion problematic. For example, at the population level we aim to reduce intakes of sodium to reduce blood pressure and risk of CVD, but for people of particular genotypes, sodium reduction may have the opposite effect ${ }^{(70)}$. Supplementation should therefore not become routine and should instead focus on individuals at risk and be applied after full evaluation of the evidence base and potential health risks. There are links, for example, between use of micronutrient supplements and cancer $^{(71)}$ which may stem from over-consumption of specific nutrients including vitamin $A$ and folic acid.

\section{Impact of ageing on nutrition and health}

Changes may occur during ageing which impact on the nutritional status of an individual as highlighted in Fig. 2. Degradation of the senses, as a result of ageing, may lead to changes in the ability to taste and smell food which, combined with the reduction in secretion of appetite hormones ${ }^{(72)}$, may impact people's levels of food consumption and choice of diets. If people selfselect smaller meals or choose not to eat there is increased risk of undernutrition which presents further health risks.

Age-related changes in Gl-tract physiology impact the oesophagus, liver, large intestine, stomach, pancreas and small intestine ${ }^{(73)}$. This can result in dysphagia, aspiration, odonphagia, gastoesophageal reflux disease (GERD) and gastroparesis which can all impact on an individuals' choice of foods and desire to eat. Malabsorption, steatorrhea and constipation can also influence food intake and nutrient absorption. Difficulty swallowing food, often alongside poor dentitition or 
wearing of dentures, may result in fewer fruit and vegetables being consumed, which ultimately has a nutritional impact on many systems, but also on gut health and function. The structure and functionality of the intestinal microbiome changes with age ${ }^{(72)}$ and long term changes in diet can with other lifestyle factors drive either acute or chronic changes in intestinal microbial ecology that are detrimental to the health of their host.

Changes to appetite and food choices with ageing, as well as physical changes to the ability to chew, swallow and absorb nutrients can lead to the suggestion that older people require supplemental nutrition. Achieving the dietary reference values for some nutrients may be problematic for some older people and as a result anaemias (iron deficiency, B vitamins) are more common in older than younger people. Routine use of supplements is not recommended for healthy people, however, with the exception of vitamin D, where current UK guidelines suggest 10ug per day, coupled with greater intake of oily fish and fortified sources. There is good evidence that this reduces the risk of osteoporotic fractures ${ }^{(74)}$. Whilst there no strong evidence base in favour of other unsupervised supplementation strategies, further guildlines are yet to be developed and must take into account concerns that other supplements could have deleterious effects such as enhancing the proliferation and spread of pre-existing tumours ${ }^{(75)}$.

\section{Impact of prenatal and infant nutrition on healthy ageing}

There is growing evidence of the impact of early life nutrition on intrinsic capacity and chronic diseases $^{(13)}$. Epidemiological evidence indicates that risk of non-communicable diseases in adult life is, in part, determined by the environment encountered in early life. Follow-up studies of historic cohorts show that CVD and type-2 diabetes are more prevalent in older people who were of lower birth weight, who were fed infant formula rather than being breast fed, or who showed rapid catchup growth in childhood ${ }^{(13)}$. These studies are supported by animal studies which directly demonstrate that caloric restriction or obesity in pregnancy compromises cardiovascular function 
and metabolism, renal function and longevity in the associated offspring. For example, offspring of rats fed a low protein diet in pregnancy have high blood pressure from the time of weaning and develop profound hepatic steatosis with ageing ${ }^{(13,76)}$.

Studies of the offspring of animals subject to under- and over-nutrition during pregnancy show that organ structure is altered by the experience, resulting in lower functional capacity at birth. As most organ development is largely complete around the time of birth, any deficits in functional units (e.g. nephrons in the kidney, islets in the pancreas) cannot be recovered, permanently altering their structure ${ }^{(13,77)}$. Whilst during earlier stages of life the capacity to fulfil organ function will be present, with ageing, the organs can no longer meet demands leading to renal failure, CVD and metabolic disturbances. Thus the early nutritional environment sets functional capacity and determines the functional profile for ageing.

\section{Lifestyle habits and choices}

Longitudinal studies highlight the influence of lifestyle habits and choices on long-term health and longevity. Levels of obesity have a direct impact on conditions such as heart disease and diabetes, whilst smoking impacts on a wide range of conditions ${ }^{(78,79)}$. Obesity has also been shown to impact on immunity and inflammation ${ }^{(80)}$. In addition, consumption of alcohol or drugs may have a broad impact on health. Antibiotics can, depending on their dose and duration, have profound and irreversible effects on the intestinal microbiota with ageing and decreased diversity of the microbiota compounding these effects ${ }^{(81)}$. More studies are required to understand the impact of over-the-counter medications and the role that the intestinal microbiota plays in determining their efficacy (xenometabolism) ${ }^{(82)}$.

The determinants of health and disease in older people are the result of complex interactions between factors operating at all stages of life (Fig 3). Environmental and lifestyle influences at any life stage are modified by genetic factors and the influences of early development. The way in which 
the body responds to the environment at each stage of life can determine the impact of lifestyle later on ${ }^{(83)}$.

Achieving healthier ageing therefore inevitably depends upon changing lifestyle at earlier life stages. Encouraging health promoting behaviour change is far from simple and there has been much interest recently in how clinicians and others in relevant positions go about offering lifestyle advice and whether there may be certain points in life, for example pregnancy and parenthood, that present 'teachable moments ${ }^{\prime(84)}$. Unless delivered in an appropriate way, a person's motivation to change often declines. Suprisingly, having bold goals for change that may be unattainable can be beneficial in some settings ${ }^{(85)}$. An interesting alternative is to make any behaviour change a habit, one that fits into a person's normal routine ${ }^{(86,87)}$. Habits are formed by repeating a specific behaviour in a certain context until it become routine, and are difficult to change once ingrained. Once this has been achieved, these habits are then triggered by specific situations. This is an example of associate learning ${ }^{(88,89,90)}$. To some extent, this negates the need for conscious motivation to perform the action. Indeed, recent evidence has shown how effective this can be in health contexts ${ }^{(87,91)}$. The changes become 'second nature' and people notice when they do not perform the behaviour ${ }^{(92)}$. There are many ways to help form such healthy habits, such as scheduling them into daily routines by setting up reminders on calendars, a tactic utilised by many smart phone apps.

\section{Mental attitude and life approach}

Studies have demonstrated causal links between personality and health conditions ${ }^{(93)}$. Ultimately if people have lower levels of conscientiousness they are more likely to make poor lifestyle choices which ultimately increase the risk of certain conditions ${ }^{(94,95)}$. Self-efficacy and self esteem are linked to resilience (the capacity to recover quickly from difficulties) which can influence the way that people approach the challenges of ageing and choose to deal with these ${ }^{(96,97)}$. This links back to the earlier definition of functional ability. 
Stress and depression can also impact on, and exacerbate, age-associated immune decline leading to increased susceptibility to infection, poor response to vaccination, greater morbidity and mortality and poor outcomes to surgery and trauma ${ }^{(98)}$.

Social interaction plays an important role in how people cope with ageing. Physical activity offers not just cardiovascular benefits but also social rewards in a group setting. Furthermore, improved cardiorespiratory function as a result of improved physical fitness and coordinated exercise routines has been shown to improve brain function ${ }^{(99)}$. Exercise has also been shown to boost mood, which will in turn influence perseverance and resilience ${ }^{(100,101)}$.

Emotion, and the ability to manage it, referred to as emotional intelligence, is vitally important. It not only improves life-satisfaction and lowers depression, but it makes the individual better at coping with stress. In terms of health, successful regulation of emotion helps the individual resist peer pressure, often a major barrier to lifestyle change ${ }^{(102)}$. Emotional intelligence is also linked to willingness to seek help and higher-quality discussions with healthcare providers ${ }^{(103)}$. One way to effect change is to create habits around specific health-change goals. Associative learning may be the basis of habit formation. Engaging the emotions in this process is also important, especially when encouraging new behaviour that is core a person's sense of self $f^{(104)}$.

Research exploring body image and health among older adults shows that, although appearance is important in terms of personal identity, being healthy and physically able is seen to be more important ${ }^{(105)}$, especially when a person experiences declining health. Indeed, health was identified as the major motivation behind changing health-related behaviour, more so than looks. Surrounding all this are sociocultural pressures to look age-appropriate, which can be inhibitory in some instances.

\section{Outcomes of the round table}




\section{Group consensus}

Upon review of the discussion at the roundtable meeting, a consensus was reached on a number of factors:

1. Individual variation in ageing/intrinsic capacity, especially at older ages. Whilst large scale studies give overarching trends, when advising and dealing with individuals it is important to remember that there is no typical older person. The heterogeneity of physiology and metabolism is greater in this population subgroup than in any other. In addition, whilst two people may have the same condition (e.g. type-2 diabetes) the contributory factors for the condition may be totally different, as may be the approach to dealing with the condition.

2. Healthy ageing requires a life course approach. Whilst desirable, it is not possible to define parameters as to when action is required to guarantee a healthier old age. Evidence demonstrates that various factors influence ageing across the entire lifespan and so a lifelong approach is required. Particular areas noted within the life course include maternal nutrition and early life and during midlife where there are often biological and social transitions. For example, protection afforded by better educational attainment in early life, along with improved health in middle life, are considered to be key to reducing the risk of dementia in later life.

3. The broader environment requires consideration. Whilst a number of factors relating to ageing have been identified that an individual could influence, including nutrition and lifestyle choices, broader factors such as environment and socioeconomic background still play a large part in determining the capacity for everyone to achieve healthy ageing.

4. There is no one key influencing factor, as the impact of ageing is often determined by a combination of factors. This makes it very difficult to reach a definitive consensus that could apply to all individuals with regards to the best way to live a longer, healthier life. It is also important to recognise that some factors such as lifestyle choices are socially patterned. 


\section{Future factors for consideration}

During the discussion a number of factors were identified for future consideration:

1. The role of medications - by the age of 65 years around $30 \%$ of people are taking multiple medications ${ }^{(106)}$. This figure is significantly greater in those with dementia and other chronic conditions . Future research should consider the additional impact of polypharmacy on the ageing process ${ }^{(107,108)}$.

2. The impact of generational resilience - many of the cohort studies incorporate the post-war generation. It is currently not known how "modern" life, with new technologies and associated social changes, will impact on the resilience of future generations.

3. The impact of current diets combined with sedentary behaviour - with the increase in the incidence of obesity and type-2 diabetes amongst younger generations consideration should be given to the impact of diet and physical activity on this generation as they age.

4. Study design - to date scientific studies have predominantly focussed on disease. Future studies need to consider changes in function during the human ageing process as opposed to focussing on just disease development or treatment effects.

\section{Conclusions}

The world is experiencing a rapid demographic shift, with life expectancy extending and a larger overall population aged over 60 years than ever before ${ }^{(1)}$. This change means that people will spend a greater proportion of their life potentially living with reduced intrinsic capacity. In addition to impacting on the individual, this will place a heavy burden on resources and health and social care services. This will be a particular challenge for developing countries, where the greatest proportion of the population increase is predicted to occur in the older populations. This panel discussion was 
convened to consider the opportunity to advise individuals on how to optimise the chance of a healthy older age.

Whilst there are certain factors including the physical environment and socioeconomic influences which are often beyond an individual's control, there is good evidence to support changes to other aspects, including lifestyle ${ }^{(83)}$, diet ${ }^{(30)}$ and physical activity, which can be taken ${ }^{(100,101)}$. In terms of cognitive function there may be a role for targeted nutritional approaches including focusing on omega-3 fatty acids, polyphenols, vitamin D and B vitamins ${ }^{(30)}$. Exercise and remaining active, as well as social interaction, have also been shown to link to better cognition and overall mood in older age and to cardiorespiratory fitness ${ }^{(100,101)}$. B vitamins and folate have been shown to directly impact vascular health, particularly related to stroke $\mathrm{e}^{(54,55)}$.

Levels of immunity in older age have been shown to be directly influenced by nutritional status, particularly micronutrients ${ }^{(59,60,61,62)}$. Links have also been shown between probiotic supplementation and improved immune response to vaccination amongst older people. Bone loss can be impacted by both calcium and vitamin $\mathrm{D}$ as well as changes in the gut microbiota ${ }^{(64,65)}$. In addition, physical activity, and healthy weight, have been shown to have a positive impact on health.

Healthcare professionals and individuals need to be aware of the broader impact of changes related to ageing which may impact on a person's ability to meet nutritional demands. Changes to the GI tract and its microbiota, appetite and also dentition can mean that individuals' diets become restricted, potentially opening a role for nutrient supplementation ${ }^{(72,73)}$. Whilst this advice may appear potentially simple, there should also be consideration of interactions between nutrients and with other factors such as medication and evaluation of potential risks ${ }^{(82)}$. Further research is needed to monitor the impact of changes and to develop a better understanding of the optimum life stage at which to take steps to promote healthy ageing.

\section{Transparency declaration}


The lead author affirms that this manuscript is an honest, accurate, and transparent account of the consensus discussion being reported. The lead author affirms that no important aspects of the work have been omitted.

\section{Acknowledgements}

The authors acknowledge the contributions of Hanson Geervarghese for his work conceptualising and supporting the meeting and Tracy Stockdale who compiled the initial version of this review from the notes made at the roundtable discussion. Azmina Govindji, Registered Dietitian, chaired the roundtable meeting.

\section{Conflicts of Interest}

Professors Calder, Carding, Langley-Evans and McNulty and Dr Christopher, declare that they received an honorarium payment for their attendance at the roundtable meeting with Merck Consumer Healthcare UK but not for writing this article. The views expressed in this review article reflect the scientific discussion at that meeting and were not commissioned by or directed by Merck Consumer Healthcare UK or any other entity.

\section{Figure Legends}

Figure 1. The functional capacity of an organ or system can be described as its ability to deliver basic requirements. It will vary across the lifespan and decline with age. Factors operating in earlier life-stages may determine whether functional capacity remains adequate in older people. Achieving a higher peak functional capacity or having slower rate of decline (A), will preserve health for longer than for a lower peak functional capacity or having a faster rate of decline (B). 
Figure 2. In elderly people, declining function in some physiological systems which impact on food choice and intake can establish a vicious cycle promoting more rapid decline.

Figure 3. The state of health at any stage of life is a product of the cumulative factors experienced across the lifespan. Complex interactions of lifestyle and current environment with genetic and epigenetic factors determine physiological and metabolic functions. 


\section{References}

1. WHO Fact sheet 404. http://www.who.int/mediacentre/factsheets/fs404/en/

2. Lafortune $\mathrm{G}$ et al. Trends in severe disability among elderly people: assessing the evidence in 12 OECD countries and the future implications. OECD Health Working Papers 26 ed. (2007)

3. Robine J et al. The relationship between longevity and healthy life expectancy. Qual Ageing (2012); 10: 5-14

4. Cooper C, Cole ZA, Holroyd CR, Earl SC, Harvey NC, Dennison EM, Melton L, Cummings SR, Kanis JA; IOF CSA Working Group on Fracture Epidemiology. Osteoporos Int. (2011 May); 22(5): 1277-88

5. Caspersen CJ, Thomas GD, Boseman LA, Beckles GL, Albright AL. Am J Public Health. (2012 Aug); 102(8): 1482-97

6. World Health Organization. World Report on Ageing and Health. Geneva: World Health Organization; (2015).

Webcitehttp://apps.who.int/iris/bitstream/10665/186463/1/9789240694811_eng.pdf?ua=1

7. Beard J et al. The World report on ageing and health: a policy framework for healthy ageing. Lancet (2016 May) 21; 387(10033): 2145-2154

8. Ben-Shlomo Y, Cooper R, Kuh D. The last two decades of life course epidemiology, and its relevance for research on ageing. Int J Epidemiol (2016 Aug) 1; 45(4): 973-88

9. Wills AK, Lawlor DA, Matthews FE et al. Life course trajectories of systolic blood pressure using longitudinal data from eight UK cohorts. PLoS Medicine (2011 Jun); 8(6): e1000440

10. Braveman PA, Cubbin C, Egerter S, Williams DR, Pamuk E. Socioeconomic disparities in health in the United States: what the patterns tell us. Am J Public Health. (2010) 100 Suppl 1: S186196.

11. Zimmer Z, Hanson HA, Smith KR. Childhood socioeconomic status, adult socioeconomic status, and old-age health trajectories: Connecting early, middle, and late life. Demographic Research. (2016) 34: 285-320.

12. McCann A, McNulty H, Rigby J, et al. Impact of area-level socioeconomic deprivation on the risk of cognitive dysfunction in older adults. J Am Ger Assoc. (2018) In Press.

13. Langley-Evans SC. Nutrition in early life and the programming of adult disease: a review. J Hum Nutr Diet. (2015 Jan);28 Suppl 1:1-14.

14. Marchand MC, Langley-Evans SC. Intrauterine programming of nephron number: the fetal flaw revisited. J Nephrol. (2001 Sep-Oct);14(5):327-31

15. Kuh D. A life course approach to healthy ageing. In Michel JP (ed). Healthy ageing: midlife prevention of age-related disability. Springer (In press)

16. Kuh D, Cooper R, Hardy R, Richards M, Ben-Shlomo Y. Editors. A life course approach to healthy ageing. $1^{\text {st }}$ ed. Oxford: Oxford University Press; (2014)

17. Davies JH, Evans BA, Gregory JW. Bone mass acquisition in healthy children. Arch Dis Child. (2005 Apr) ;90(4):373-8. 
18. Kuh D, Muthuri S, Cooper R, Moore A, MacKinnon K, Cooper C, Adams JE, Hardy R*, Hardy $\mathrm{K}^{*}$. Menopause, reproductive life hormone replacement therapy and bone phenotype at age 60-64: a British birth cohort. Journal of Clinical Endocrinology and Metabolism (2016 Jul) 29; JC: 20161828. ( $*$ joint authors)

19. Jordan KM, Syddall H, Dennison EM, Cooper C, Arden NK. Birthweight, vitamin D receptor gene polymorphism, and risk of lumbar spine osteoarthritis. J Rheumatol. (2005 Apr);32(4):678-83.

20. Boreham CA, McKay HA. Physical activity in childhood and bone health. Br J Sports Med. (2011 Sep);45(11):877-9.

21. Stear SJ, Prentice A, Jones SC, Cole TJ. Effect of a calcium and exercise intervention on the bone mineral status of 16-18-y-old adolescent girls. Am J Clin Nutr. (2003 Apr);77(4):985-92.

22. Dodds RM, Syddall HE, Cooper R et al. Grip strength across the life course: normative data from twelve British studies. PLoS ONE (2014); 9(12): e113637

23. Nahhas RW1, Choh AC, Lee M, Chumlea WM, Duren DL, Siervogel RM, Sherwood RJ, Towne B, Czerwinski SA. Bayesian longitudinal plateau model of adult grip strength. Am H Hum Biol. (2010 Sep-Oct); 22(5): 648-56: doi: 10.1002/ajhb. 21057

24. Lange $P$, Celli B, Agusti $A$ et al. Lung-function Trajectories Leading to Chronic Obstructive Pulmonary Disease. N Engl J Med (2015 Jul) 9; 373(2): 111-22

25. World Health Organisation. (2016) Mental health and older adults. Updated December 2017 WHO; available at: http://www.who.int/mediacentre/factsheets/fs381/en/ (accessed 09/12/2017)

26. Prince M, Comas-Herrera A, Knapp M et al. (2016) World Alzheimer Report 2016 Improving healthcare for people living with dementia coverage, Quality and costs now and in the future . London: Alzheimer's Disease International (ADI), London

27. Gauthier S, Reisberg B, Zaudig M et al. Mild cognitive impairment. Lancet 367, (2006); 9518 : 1262-1270.

28. Livingston $G$, Sommerlad A, Orgeta V, et al. Dementia prevention, intervention, and care. The Lancet. 2017. Published online (July 20, 2017) http://dx.doi.org/10.1016/S0140-6736(17)313636.

29. Sutin AR, Stephan Y, Terracciano A. Int J Geriatr Psychiatry. (2018 Jan) 3. doi: 10.1002/gps.4849

30. Moore K, Hughes CF, Ward M, Hoey L and McNulty H. Diet, nutrition and the ageing brain: current evidence and new directions. Proceedings of the nutrition society. (2018). Doi.org/10/1017/S0029665117004177

31. Kang JH, Ascherio A, Grodstein F. Fruit and vegetable consumption and cognitive decline in aging women. Ann Neurol (2005) 57; 5: 713-720.

32. Barberger-Gateau $P$, Raffaitin $C$, Letenneur $L$ et al. Dietary patterns and risk of dementia: the Three-City cohort study. Neurology (2007) 69; 20: 1921-1930.

33. Camargo A, Delgado-Lista J, Garcia-Rios A, Cruz-Teno C, Yubero-Serrano EM, Perez-Martinez $\mathrm{P}$, et al. Expression of proinflammatory, proatherogenic genes is reduced by the Mediterranean diet in elderly people. Br J Nutr (2012); 108(3):500-8. doi:10.1017/s0007114511005812 27. 
34. Mena MP, Sacanella E, Vazquez-Agell M, Morales M, Fitó M, Escoda R, et al. Inhibition of circulating immune cell activation: a molecular antiinflamma-tory effect of the Mediterranean diet. Am J Clin Nutr (2009) 89(1):248-56. doi:10.3945/ajcn.2008.26094

35. Staubo SC, Mielke MM, Petersen RC et al. Mediterranean diet, micronutrients and macronutrients, and MRI measures of cortical thickness. Alzheimers Dement. (2017) 13; 2: 168-177.

36. Valls-Pedret C, Sala-Vila A, Serra-Mir M et al. Mediterranean Diet and Age-Related Cognitive Decline: A Randomized Clinical Trial. JAMA Intern Med (2015) 175; 7: 1094-1103.

37. Mazereeuw G, Lanctot KL, Chau SA et al. Effects of omega-3 fatty acids on cognitive performance: a meta-analysis. Neurobiol Aging (2012) 33; 7: 1482.e17-1482.e29.

38. Burckhardt M, Herke M, Wustmann T et al. (2016) Omega-3 fatty acids for the treatment of dementia. Cochrane Database Syst Rev 4, CD009002.

39. Brickman AM, Khan UA, Provenzano FA et al. Enhancing dentate gyrus function with dietary flavanols improves cognition in older adults. Nat Neurosci (2014) 17; 12: 1798-1803.

40. Annweiler C, Montero-Odasso M, Llewellyn DJ et al. Meta-analysis of memory and executive dysfunctions in relation to vitamin D. J Alzheimers Dis (2013) 37; 1: 147-171.

41. Miller JW, Harvey DJ, Beckett LA et al. Vitamin D status and rates of cognitive decline in a multiethnic cohort of older adults. JAMA Neurol (2015) 72; 11: 1295-1303.

42. Hooshmand B, Lökk J, Solomon A et al. Vitamin D in relation to cognitive impairment, cerebrospinal fluid biomarkers, and brain volumes. J Gerontol A Biol Sci Med Sci (2014) 69; 9: 11321138.

43. Smith AD, Refsum H. Homocysteine, B Vitamins, and Cognitive Impairment. Annu Rev Nutr (2016) 36:211-239.

44. Degnan P H, Taga ME and Goodman A L. Vitamin B12 as a Modulator of Gut Microbial Ecology. Cell Metabolism (2014); 20: 769-778

45. Durga J, van Boxtel M,P.J., Schouten EG et al. Articles: Effect of 3-year folic acid supplementation on cognitive function in older adults in the FACIT trial: a randomised, double blind, controlled trial. Lancet (2007) 369: 208-216.

46. de Jager C, Oulhaj A, Jacoby R et al. Cognitive and clinical outcomes of homocysteinelowering B-vitamin treatment in mild cognitive impairment: a randomized controlled trial. Int J Geriatr Psychiatry (2012) 27; 6: 592-600.

47. Smith $A D$, de Jager $C A$, Whitbread $P$ et al. Homocysteine-lowering by $B$ vitamins slows the rate of accelerated brain atrophy in mild cognitive impairment: A randomized controlled trial. PLoS One (2010) 5; 9: 1-10.

48. Douaud G, Nichols TE, Smith SM et al. Preventing Alzheimer's disease-related gray matter atrophy by B-vitamin treatment. Proc Natl Acad Sci U S A (2013) 110; 23: 9523-9528.

49. Clarke $R$, Bennett $D$, Parish $S$ et al. Effects of homocysteine lowering with $B$ vitamins on cognitive aging: Meta-analysis of 11 trials with cognitive data on 22,000 individuals. Am J Clin Nutr (2014) 100; 2: 657-666. 
50. Garrard P, Jacoby R. B-vitamin trials meta-analysis: less than meets the eye. Am J Clin Nutr (2015) 101; 2: 414-415.

51. Peters SA, Woodward M. Women's reproductive factors and incident cardiovascular disease in the UK Biobank. Heart (2018 Jan) 15. Pil:heart-jnl-2017-312289. Doi:10.1136/heart-jnl-2017312289 (Epub ahead of print)

52. Romagnani P, Remuzzi G, Glassock R, Levin A, Jager KJ, Tonelli M, Massy Z, Wanner C, Anders HJ. Chronic Kidney Disease. Nat Rev Dis Primers. (2017 Nov) 23;3: 17088

53. Ostan R, Bucci L, Capri M, Salvioli S, Scurti M, Pini E, et al. Immunosenescence and immunogenetics of human longevity. Neuroimmunomodulation (2008) 15:224-40. doi:10.1159/000156466

54. Tian T, Yang KQ, Cui JG, Zhou LL. Folic Acid Supplementation for Stroke Prevention in Patients with Cardiovascular Disease. Am J Med Sci. (2017 Oct); 354(4): 379-387.

55. Moat SJ. Plasma total homocysteine: instigator or indicator of cardiovascular disease? Ann Clin Biochem. (2008 Jul); 45(Pt 4): 345-8

56. Pawelec G, Larbi A, Derhovanessian E. Senescence of the human immune system. J Comp Pathol. (2010 Jan); 142 Suppl 1: S39-44

57. Goodwin K, Viboud C, Simonsen L. Antibody response to influenza vaccination in the elderly: a quanititative review. (2006 Feb) 20; 24(8): 1159-69

58. Palmer DB. The effect of age on thymic function. Front Immunol. (2013 Oct) 7; 4: 316

59. Ahluwalia et al. Am J Clin Nutr. (2004) 79, 516-521.

60. Molls $\mathrm{R}$ et al. Nutritional status predicts primary subclasses of T cells and the lymphocyte proliferartion response in healthy older women. J Nutr. (2005) 135: 2644-2650.

61. Meydani S et al. Vitamin E supplementation enhances cell-mediated immunity in healthy elder subjects. Am J Clin Nutr. (1990); 52: 557-63

62. Duchateau J et al. Beneficial effects of oral zinc supplementation on the immune response of old people. Am J Med. (1981); 70: 1001-4

63. Bog J et al. Zinc and immunocompetence in the elderly: baseline data on zinc nuriture and immunity in unsupplemented subjects. Am J Clin Nutr (1987); 46: 101-9

64. Dawson-Hughes B, Harris SS, Krall EA, Dallal GE. Effect of withdrawal of calcium and vitamin D supplements on bone mass in elderly men and women. Am J Clin Nutr. (2000 Sep);72(3):745-50.

65. Bischoff-Ferrari HA, Dawson-Hughes B, Willett WC, Staehelin HB, Bazemore MG, Zee RY, Wong JB. Effect of Vitamin D on falls: a meta-analysis. JAMA. (2004 Apr) 28;291(16):1999-2006.

66. Hallström H, Wolk A, Glynn A, Michaëlsson K, Byberg L. Coffee consumption and risk of fracture in the Cohort of Swedish Men (COSM). PLoS One. (2014 May) 15;9(5):e97770.

67. Tousen Y, Ezaki J, Fujii Y, Ueno T, Nishimuta M, Ishimi Y. Natural S-equol decreases bone resorption in postmenopausal, non-equol-producing Japanese women: a pilot randomized, placebocontrolled trial. Menopause. (2011 May); 18(5):563-74. 
68. Tipton KD. Muscle protein metabolism in the elderly: influence of exercise and nutrition. Can J Appl Physiol. (2001 Dec); 26(6): 588-606

69. Bolland MJ, Grey A, Avenell A, Gamble GD, Reid IR. Calcium supplements with or without vitamin $D$ and risk of cardiovascular events: reanalysis of the Women's Health Initiative limited access dataset and meta-analysis. BMJ. (2011 Apr) 19;342:d2040.

70. Chen J. Sodium sensitivity of blood pressure in Chinese populations. Curr Hypertens Rep. (2010 Apr); 12(2):127-34.

71. Bjelakovic G, Nikolova D, Simonetti RG, Gluud C. Antioxidant supplements for prevention of gastrointestinal cancers: a systematic review and meta-analysis. Lancet. (2004 Oct) 28;364(9441):1219-28.

72. Pilgrim AL, Robinson SM, Sayer AA, Roberts, HC An overview of appetite decline in older people. Nursing Older People. (2015) 27, 5, 29-35

73. Nigam Y, Knight J Anatomy and physiology of ageing (2017) 3: the digestive system. Nursing Times; 113: 4, 54-57.

74. Bischoff-Ferarri HA, Dawson-Hughes B, Staehelin HB, Orav JE, Stuck AE, Theirler R, Wong JB, Egli A, Kiel DP, Henschjowski J. Fall prevention with supplemental and active forms of vitamin D: a meta-analysis of randomised controlled trials. BMJ. (2009 Oct) 1;339: b3692

75. Buhr G, Bales CW. Nutritional supplements for older adults: review and recommendations Part II. J Nutr Elder. (2010 Jan) ;29(1): 42-71

76. Erhuma A, Salter AM, Sculley DV, Langley-Evans SC, Bennett AJ. Prenatal exposure to a lowprotein diet programs disordered regulation of lipid metabolism in the aging rat. Am J Physiol Endocrinol Metab. (2007 Jun) ;292(6):E1702-14.

77. Swali A, McMullen S, Hayes H, Gambling L, McArdle HJ, Langley-Evans SC. Cell cycle regulation and cytoskeletal remodelling are critical processes in the nutritional programming of embryonic development. PLoS One. (2011) ;6(8):e23189

78. Samet JM. Tobacco smoking: the leading cause of preventable disease worldwide. Thorac Surg Clin. (2013 May) ;23(2): 103-12

79. Tanaka K, Nakanishi T. Obesity as a risk factor for various diseases: necessity of lifestyle changes for healthy ageing. Appl Human Sci. (1996 Jul) ;15(4): 139-48

80. Frasca D, Blomberg BB, Paganelli R. Ageing, Obesity and Inflammatory Related Diseases. Front Immuno. (2017 Dec) 7;8: 1745

81. Lakshminarayanan B, Stanton C, O'Toole PW, Ross RP. Compositional dynamics of the human intestinal microbiota with aging: implications for health. J Nutr Health Aging. (2014 Nov) ;18(9): 773-86

82. Campbell C, Grapov D, Fiehn O, Chandler CJ, Burnett DJ, Souza EC, Casazza GA, Gustafson MB, Keim NL, Newman JW, Hunter GR, Fernandez JR, Garvey WT, Harper ME, Hoppel CL, Meissen JK, Take K, Adams SH. Improved metabolic health alters host metabolism in parallel with changes in systemic xeno-metabolites of gut origin. PLoS One. (2014 Jan) 8;9(1): e84260 
83. Langley-Evans SC, McMullen S. Developmental origins of adult disease. Med Princ Pract. (2010) ;19(2): 87-98

84. Swift JA, Langley-Evans SC, Pearce J, Jethwa PH, Taylor MA, Avery A, Ellis S, McMullen S, Elliott-Sale KJ. Antenatal weight management: Diet, physical activity, and gestational weight gain in early pregnancy. Midwifery. (2007 Jun) ;49: 40-46

85. Avery A, Langley-Evans SC, Harrington M, Swift J. Setting targets leads to greater long-term weight losses and 'unrealistic' targets increase the effect in a large community-based commercial weight management group. J Hum Nutr Diet. (2016 Dec) ; 29(6): 687-696

86. Making health habitual: the psychology of 'habit-formation' and general practice. Benjamin Gardner, Phillippa Lally and Jane Wardle. Br J Gen Pract (2012) ; 62 (605): 664-666. DOI: https://doi.org/10.3399/bjgp12X659466

87. Rothman AJ, Sheeran P, Wood W. Reflective and automatic processes in the initiation and maintenance of dietary change. Ann Behav Med (2009) ; 38(Suppl1): S4-17

88. Bayley PJ, Frascino JC, Squire LR. Robust habit learning in the absence of awareness and independent of the medial temporal lobe. Nature (2005) ; 436(7050): 550-553.

89. Hull CL. Principles of behavior: an introduction to behavior theory. New York, NY: AppletonCentury-Crofts, (1943).

90. Lally $\mathrm{P}$, van Jaarsveld CHM, Potts HWW, Wardle J. How are habits formed: modelling habit formation in the real world. Euro J Soc Psychol (2010); 40: 998-1009.

91. Lally P, Gardner B. Promoting habit formation. Health Psychol Rev . In press: DOI: 10.1080/17437199.2011.603640.

92. Lally P, Wardle J, Gardner B. Experiences of habit formation: a qualitative study. Psychol Health Med (2011); 16(4): 484-489.

93. Christopher $\mathrm{G}$ (2013). The psychology of ageing: from mind to society. Palgrave Macmillan.

94. Pulkki-Raback, L., Elovainio, M., Kivimaki, M., Raitakari, O. T., \& Keltikangas-Jarvinen, L.. Temperament in childhood predicts body mass in adulthood: The cardiovascular risk in young Finns study. [Research Support, Non-U.S. Gov't]. Health 9780230337213_Psychology: Official Journal of the Division of Health Psychology, American Psychological Association, (2005); 24(3): 307-315. doi: 10.1037/0278-6133.24.3.307.

95. Terracciano, A. \& Costa, P. T., Jr.. Smoking and the Five-Factor Model of personality Addiction, (2004); 99(4): 472-481. doi: 10.1111/j.1360-0443.2004.00687.x

96. Bandura, A. (2004). Self-efficacy. In W. E. Craighead \& C. B. Nemeroff (Eds), The concise Corsini encyclopedia of psychology and behavioral science (3rd edn, pp. 1534-1536). New York; Chichester: Wiley.

97. Gallagher J, Mitchell C, Heslop L and Christopher G. Reslience to health related adversity in older people. Quality in Ageing and Older Adults (2012); 13(3): 197-204

98. Gouin, J. P., Hantsoo, L., \& Kiecolt-Glaser, J. K. (2008). Immune dysregulation and chronic stress among older adults: A review. [Research Support, N.I.H., Extramural; Research Support, NonU.S. Gov't; Review]. Neuroimmunomodulation, 15(4-6), 251-259. doi: 10.1159/000156468 
99. Colcombe, S. J., Erickson, K. I., Raz, N., Webb, A. G., Cohen, N. J., McAuley, E., \& Kramer, A. F. Aerobic fitness reduces brain tissue loss in aging humans. [Comparative Study; Research Support, U.S. Gov't, P.H.S.]. Journals of Gerontology Series A: Biological Sciences and Medical Sciences, (2003); 58(2): 176-180.

100. Boyce, N., Walker, Z., \& Rodda, J. (2008). The old age psychiatry handbook: A practical guide. Chichester: John Wiley \& Sons Ltd.

101. Karwoski, L., McCurdy, D., \& Mccurdy, D. (2009). Exercise and depression. In R. E. Ingram (Ed.), The international encyclopedia of depression. New York ; London: Springer.

102. Trinidad, D. R., \& Johnson, C. A.. The association between emotional intelligence and early adolescent tobacco and alcohol use. Personality and individual differences, (2002); 32(1), 95-105.

103. Ciarrochi, J. V., \& Deane, F. P. Emotional competence and willingness to seek help from professional and nonprofessional sources. British Journal of Guidance and Counselling, (2001); 29(2), 233-246.

104. Cherniss, C., Goleman, D., Emmerling, R., Cowan, K., \& Adler, M. (1998). Bringing emotional intelligence to the workplace. New Brunswick, NJ: Consortium for Research on Emotional Intelligence in Organizations, Rutgers University.

105. Jankowski G, Diedrichs PC, Williamson H, Harcourt D \& Christopher G Looking ageappropriate whilst growing old gracefully: A qualitative study of ageing and body image among older adults. Journal of Health Psychology (2016); 21(4): 550-61. ISSN 1359-1053

106. Castioni J, Marques-Vidal P, Abolhassani N, Vollenweider P, Waeber G. Prevalence and determinants of polypharmacy in Switzerland: data from the CoLaus study. BMC Health Serv Res. (2017 Dec) 21;17(1): 840. Doi: 10.1186/s12913-017-2793-z

107. Barry HE, Cooper JA, Ryan C, Passmore AP, Robinson AL, Molly GJ, Darcy CM, Buchanan H, Hughes CM. J Alzheimers Dis. (2016 Apr) 11;52(4): 1503-13

108. Rawle $M$, Cooper R, Kuh D, Richards $M$. The associations of polypharmacy with cognitive and physical capability in the seventh decade: findings from a British birth cohort study. Journal of the American Geriatrics Society. (2018) 
